\title{
Weak links in the chain of authority: The challenges of intervention decisions to protect civilians
}

The United Nations Security Council mandates peacekeeping operations to protect civilians, and regularly authorizes operations to use force to achieve this objective. Yet in the challenging situations facing contemporary peacekeeping operations, local civilians remain vulnerable to extreme violence. One set of reasons for this unwelcome result surrounds the decisions to forcefully protect civilians in any given context. This paper describes why peacekeeping operations vest discretion over the use of robust force across multiple agents. Using signal detection theory to model the decision-making of these agents, our analysis shows how the iterative nature of the decision-making gives rise to a chain of authority where the most conservative decision-maker tends to prove decisive. With this analysis in tow, we turn our attention to recent protection initiatives, including Security Council Resolution 2098 (2013) and its controversial mandate for the new 'Intervention Brigade' in the Democratic Republic of the Congo.

Keywords: Peacekeeping; protection of civilians; signal detection theory; decision-making; Security Council Resolution 2098; MONUSCO.

The United Nations (UN) Security Council regularly mandates peacekeeping operations (PKOs) to protect civilians, and in principle authorizes operations to use force to achieve this objective. ${ }^{1}$ Despite this, local civilians often remain vulnerable to violence. In this paper we explore one set of reasons explaining this continued vulnerability, focusing on the nature of decisions to employ force to protect civilians. Using signal detection theory to model decision-making, we show how systemic factors (impacting on an entire region or conflict) and decentralized factors (recognized by local agents at the coalface) influence decisions to employ force in a given context. This combination of factors emerging at different levels of 
decision-making means that a wide array of actors must agree before the PKO employs robust force. As a result, the most conservative agent (the decision-maker most reluctant to employ force) tends to prove decisive-helping explain why civilians can remain unprotected even when in the vicinity of an apparently well-resourced PKO. While political dynamics shift with each different operation, and over time, these contingent factors inevitably feed into a larger, iterative decision-making structure where the most conservative agent often holds a veto on robust force.

Our argument proceeds as follows. The first section outlines signal detection theory, as a helpful method of modelling how decision-makers make decisions to intervene. The second section then describes the 'authorization chain', arguing that decision-makers at several different levels make decisions about peacekeepers deploying and employing force. Using signal detection theory to model decision-making at each of these levels, we note how different decision-makers respond to different factors. Because of the nature of the process, each decision-maker might effectively hold a veto over the use of robust force in any given instance. By showing why protection efforts tend to be controlled by the most conservative actor, the analysis explains why civilians remain vulnerable. In the third section we assess several recent developments in peacekeeping civilian protection, especially the 'Intervention Brigade’ authorized in UN Security Council (UNSC) Resolution 2098 of March 2013—a development hailed as breaking into 'new territory' for the United Nations. ${ }^{2}$

\section{Modelling intervention decisions}

Signal detection theory (SDT) provides a way of modelling intervention decisions - that is, decisions made by agents about whether to intervene in a specific situation that has the potential to go terribly wrong, or whether to allow it to run its course unchecked in the hope 
that it doesn't. Theorists spanning many disciplines have employed SDT to understand and appraise decision-making in such situations, especially in environments when failures to intervene can draw sharp criticism. ${ }^{3}$

Importantly, SDT distinguishes between the quality of the information available to the decision-maker, and a 'response criterion' (the threshold of how much evidence a decisionmaker requires before intervening). These two variables can change independently of each other. ${ }^{4}$ Beginning with the first variable, in SDT 'sensitivity' $(S)^{5}$ describes the quality of the available information, that is, the information's known capacity to discriminate between situations demanding a response, and situations where a response is unnecessary. Two factors create sensitivity: the accuracy of the information (e.g. 'Are militia putting up roadblocks, or not?'), and the likelihood that the information implies a situation demanding response (e.g. 'Does the roadblock's control over peacekeeper mobility preface an attack on civilians?'). The greater the sensitivity of the information, the more a decision-maker can be confident that the information entails the presence of an underlying cause of real concern, rather than merely background noise. In the situations considered by SDT, however, sensitivity never rises to perfection. The received information probabilistically implies an event of concern without unequivocally determining its presence, leaving decision-makers needing to make judgment calls about when to act.

In order to explain these judgment calls, SDT employs the second variable: a 'response criterion' (denoted as $\beta$ ). The response criterion describes the threshold point where a decision-maker decides the gravity of the received information has reached a pitch where she will intervene. As compared to sensitivity, different factors govern the placement of $\beta$ particularly the payoffs to the decision-maker of each of the possible outcomes. SDT allows for four possible outcomes: hits, correct rejections, misses and false alarms. Applied to 
peacekeeping interventions employing robust force, hits mean that the PKO intervenes when intervention is required; correct rejections mean they resist intervening when intervention is unnecessary; misses mean they fail to intervene when intervention is called for; and false alarms mean they intervene unnecessarily. Naturally, the decision-maker will want to place her value of $\beta$ in such a way as to lessen the probability of misses and false alarms, and raise the probability of hits and correct rejections. But she possesses no perfect method to accomplish this result; lowering $\beta$ heightens her chances of false alarms even as it raises her chances of hits. Raising $\beta$ improves her chances of correct rejections but raises her chances of misses. Ultimately, the particular costs and benefits the decision-maker assigns to each of the four outcomes determine where she places $\beta$. For example, if the peacekeeping decisionmaker fears the dire ramifications of a false alarm outcome (that is, she intervenes forcefully in a case that did not merit it), then she will raise her value of $\beta$-notwithstanding that this creates a higher likelihood of misses (failing to intervene robustly when intervention was necessary). On the other hand, if she vows 'never again’ and lowers her value of $\beta$ to avoid repeating disastrous protection failures (consider Rwanda and Srebrenica), then she unavoidably inflates her chances of unnecessary interventions.

Such compromises, however, constitute only the beginning of the challenges for peacekeeping decision-makers contemplating robust force. For each agent's decision to intervene amounts to just one iteration in a larger chain of authority—a process inevitably privileging the most conservative decision-maker. The following section uses SDT to show how and why this privileging occurs. In drawing on SDT we do not aim to supplant other theoretical approaches, such as modelling specific agent's decision-making on the basis of rational pursuit of expected utility. ${ }^{6}$ Rather, as we show, the SDT analysis provides a tractable device for illustrating the workings of an iterative, multi-level decision-making process, in particular by highlighting how different decision-making nodes within that larger 
chain can diverge on the quality $(S)$ and quantity of their information, and also on the factors governing their threshold for action $(\beta)$. As we illustrate, while scholarly focus on specific decision-making levels is valuable, we can only appreciate the full array of factors impacting upon robust protection when we draw back and conceive the larger multi-level chain of decision-making.

\section{The chain of authority}

Different decision-makers can hold different reasons for resisting robust protection. Even when they share objectives, decision-makers can attach different priorities to those objectives. The following account details the major reasons pressing against robust protective action for each decision-maker in the chain of authority, from the UN Security Council, to the UN Secretariat, force-command, the troop contributor countries and individual troops themselves. (For simplicity we focus on role-holders within these institutions, but differences arise even between institutional role-holders-differences influencing their placement of the intervention threshold $\beta$.)

We need to balance this presentation of reasons against robust protective action with each agent's positive reasons for undertaking protective action. Four main reasons press decisionmakers to use robust force, and thus to lower $\beta$, their threshold for action: a moral concern for preventing egregious violations of human rights; a political concern for reputational costs — especially the costs of being seen as blocking vital protection activities; a strategic concern for avoiding the potentially disruptive ramifications of atrocities left unchecked; and a personal sense of ownership through achieving protection outcomes and fulfilling one's institutional responsibilities. All protection actors presumably display some concern for each of these four reasons, though they will evince different degrees of concern for each. For 
example, we might expect peacekeepers on the ground to feel the moral call to protect local civilians under imminent threat more acutely than Security Council members in New York.

The executive level: United Nations Security Council

For UN operations, the Security Council authorizes the PKO by determining its mandate. The mandate outlines the objectives of the PKO, its makeup and resources, and its capacity to use force to attain those objectives. The Council decides whether to authorize robust force under Chapter VII of the UN Charter (a common occurrence nowadays), and whether to prioritize the objective of civilian protection. ${ }^{7}$ Unlike other actors in the chain of authority, the Council can only authorize in general terms the PKO's use of force, rather than directing it in any given instance to actually employ force. While the subject of Council Member's decisionmaking therefore differs crucially from other decision-makers in the chain of decisionmaking, Council Member’s judgments on lower-level operational decisions still carry weight. As well as commenting directly on operational issues through its delegations, the Council can censure lower-level actors it perceives to have over-stepped on the use of force, and it can alter its decision-making to stymie repeat episodes of over-stepping. Côte d'Ivoire in early 2011 provides a clear example, where the Secretary-General chose to employ attack helicopters against the heavy weapons of Laurent Gbagbo's forces. ${ }^{8}$ Russia, China and India all criticized the Secretary-General's operational decision, even querying its legality. Some reports suggested Russia was incensed enough to consider vetoing Ban Ki-Moon’s second term as Secretary-General. ${ }^{9}$ As such, while lower level decision-makers will never use force without standing authorization from the Council, decision-makers might still resist employing authorized force if messages coming from the Council betray a lack of support.

Several factors can prompt the Council to set a high $\beta$ for authorizing or supporting the use of robust force. Allowing PKOs to use force to protect civilians threatens the status of the 
United Nations as an 'honest broker, not a potential party to the conflict' ${ }^{10}$ and it risks miring the PKO in local disputes, and potentially even in conflict with incumbent state regimes. ${ }^{11}$ As far back as 1995, Boutros Boutros-Ghali observed that PKOs’ protection of civilians blurred the distinction between peacekeeping and enforcement, leading to the disasters in Somalia, and in Bosnia and Herzegovina. ${ }^{12}$ Unfortunately, the Council's discretion on setting $\beta$ also creates opportunities for Council Members to raise the threshold value for self-interested reasons, such as narrow security, economic and geopolitical interests. Darfur presents a plausible example where China blocked any possibility of a robust PKO for such reasons. ${ }^{13}$

The administrative level: United Nations Secretariat

After the Security Council mandate, the UN Secretariat, including the Department of Peacekeeping Operations (DPKO) and the Department of Field Support (DFS), takes over implementation of the mission. Like the Security Council, the administrative level's control over the PKO can both provide a standing consent to engage and can influence specific lower-level decisions. But unlike the Council, the Secretary-General can also make specific operational decisions to pull the trigger on employing force. The aforementioned case of Cote d'Ivoire in 2011 provides an example of positive action, while the case of Rwanda in 1995 remains a telling case of the Secretariat vetoing a lower-level decision to pro-actively protect civilians. $^{14}$

The administrative level requires discretionary control over the use of robust force for several reasons. As a priority, the administrative level must consider the geopolitical impact created by the arrival of a robust PKO. The PKO might play into the hands of the state by effectively maintaining the status quo, or succor insurgents by shielding civilian areas (comprising their base of operations) from reprisals. The PKO might also lull civilians into a false sense of security, thus indirectly slowing or even halting local attempts at protection and resistance. ${ }^{15}$ 
As well, a robust authorization for force risks raising the expectations of the vulnerable population, potentially leading to dismay, anger and violence if the PKO fails to meet these expectations. ${ }^{16}$ The PKO might even contribute to ethnic cleansing by encouraging the movements of civilians away from their homes to safe areas and refugee camps.

As well as these geopolitical concerns, the administrative level must consider the impact robust protective actions might have on other PKO objectives. These other objectives, which will also concern local force commanders (see below), can include disarming and demilitarizing groups or territories, promoting secure delivery of humanitarian aid, monitoring ceasefires and demilitarized and weapons-secure zones, facilitating and monitoring peace agreements and elections, protecting political figures and the rights of vulnerable groups, and bringing war criminals to justice. Of course, we do not wish to overplay the distinction between these objectives and the protection of civilians, as violence to civilians can sunder other efforts to promote peace. ${ }^{17}$ However, resources stretched to accommodate one objective are rendered unavailable for others, and tensions can emerge between even closely related peacekeeper objectives, such as security-sector reform and the protection of civilians. ${ }^{18}$ These reasons heighten the administrative level's threshold for action, $\beta$, both in terms of its general guidance on the use of force, and its response to specific employments of force. Unfortunately, self-serving factors (e.g. risk-aversion) can also inflate the Secretariat's positioning of $\beta$.

\section{The force-command level}

Local force commanders_ — civil and military_-lead the PKO on the ground. As well as sharing many of the concerns of the administrative level, force commanders have their own reasons to assign a high $\beta .{ }^{19}$ Force-commanders will be sensitive to the risks their actions 
create for the PKO itself, and its capacity to pursue other force objectives. The use of force even in a single discrete situation might trigger a party to the conflict—or even the host-state itself-to withdraw its consent to the PKO. Such force may spark risks to the PKO, to local humanitarian actors, and even to civilians, and can spur belligerent reprisals, hostage-taking and non-cooperation. Rupert Smith, force commander of UNPROFOR in Bosnia, has described how PKOs protecting populations in safe areas confront a 'hostage-shield' situation. ${ }^{20}$ The PKO supplies a shield for protected populations to shelter behind, even as those populations pursue their own strategic objectives. At the same time, the surrounding force usually holds the raw power to attack the PKO with overwhelming force at any time, effectively holding it hostage.

Force commanders possess additional motives to raise their $\beta$. In some cases, belligerents orchestrate violence against civilians to provoke the PKO into a robust response, thereby justifying the belligerent's retaliations. ${ }^{21}$ Because the PKO force may harm civilians in the course of its robust protection initiatives, force commanders also face serious moral and legal risks. $^{22}$ Insurgents or state-sponsored militia rarely abide by the laws of war, and can be hard to distinguish from non-combatants. The resulting risks of collateral damage increase $\beta$. As the force commander of the UN PKO in Haiti observed:

I have been accused of not being aggressive enough, and now I have been labeled as timid. I don’t know if that's true, but I do know that I am prudent, thank God, because imprudence can lead to a court martial. ${ }^{23}$

After the PKO took more robust action, critics duly censured the mission for itself becoming a threat to civilians. ${ }^{24}$ Even if the PKO avoids committing rights violations itself, it may operate alongside less constrained forces —an ongoing problem with the UN PKO in the Democratic Republic of the Congo (DRC): MONUSCO (previously 
MONUC). ${ }^{25}$ As well, forceful demilitarization of safe areas takes on a more sinister aspect if those areas subsequently come under attack.

The robust protection of civilians, in other words, opens a PKO to a myriad of almost inevitable moral accusations. These accusations carry material consequences. John Sanderson, military commander of the UN PKO in Cambodia (UNTAC), stressed the importance of the PKO's moral authority, observing the host of factors eroding it, and how a successful operation often becomes 'a race against time to complete the mission objectives before you run out of momentum'. ${ }^{26}$

Returning to the larger argument, there are thus four separate types of concerns—risks to other force objectives, risks of reprisals, strategic geopolitical considerations, and moral risks — that can legitimately impel a force commander to adopt a high value of $\beta$ and thus resist authorizing robust force in any particular instance, or as a matter of general policy in the PKO’s standing rules of engagement (ROE).

One additional factor impacts on both administrative and force-command decisionmaking: the need to ensure continuing support from countries providing troops and police personnel.

The troop and police contributing country

No country likes to see its soldiers being killed, especially in foreign lands where it holds no vital interests. Troop and policy contributing countries (TPCCs) understandably evince concern when policies of robust protection elevate the risks to their peacekeepers. Peacekeeper fatalities can even trigger precipitous withdrawal from a mission (such as with the US in Somalia). ${ }^{27}$ The heightened risk of casualties also impacts on the TPCC's domestic support for, and perception of, the PKO. Higher risks to its soldiers, combined with increased 
controversy over the role of the PKO, mean that TPCC domestic support can weigh against robust protective action, ${ }^{28}$ encouraging TPCCs to raise their $\beta .{ }^{29}$ As a result, TPCCs may draft their own, more conservative ROE. Domestic law, policy and training can also constrain the troops, and TPCCs can even maintain direct control over their forces, leading to parallel chains of command. ${ }^{30}$

The troops themselves

Like their higher level authorities, troops can hesitate to use robust force because of concerns with moral and legal risks, and also because of uncertainty about the system-wide consequences of such force (e.g., the likelihood of reprisal attacks). The troops will also want to avoid exacerbating the risks to their own lives. In using robust force against belligerents, PKO troops raise the likelihood that deadly force will be returned against them. The specific context of peacekeeping amplifies this risk. As distinct from standard military operations, PKOs usually do not enjoy quick response or medical evacuation capacities, making a sudden escalation in conflict more dangerous. ${ }^{31}$ As a result of such factors, peacekeeping operations in the DRC have failed to protect civilians, ${ }^{32}$ while Rwanda remains the signature example of 'a lack of will to commit to peacekeeping, and above all, to take risks in the field'. ${ }^{33}$

This unwillingness to take risks matters because peacekeeping protective tasks often devolve to the discretionary decision-making of the actors on the ground. For this reason commentators speak of protection as a 'decentralized' activity. ${ }^{34}$ Even if peacekeepers in the field do not, strictly speaking, have authority over whether to act, local troops can often control the sensitivity $(S)$ of the information possessed by higher levels of command. They can make conservative estimates of dangers to civilians, or misreport facts on the ground. ${ }^{35}$ In such situations, the troops can allow their high values of $\beta$ to decisively decrease the $S$ of 
their superior's information, effectively adding a final layer to the chain of decisionmaking. ${ }^{36}$

Some might consider that the entrenched military culture of peacekeeping soldiers might mitigate this problem by fuelling enthusiasm for responding to problems by employing force ${ }^{37}$ However, even if a militarist ethos does sometimes incline peacekeepers to employ force for the specific purpose of civilian protection, the need for higher authority and the concern for the system-wide ramifications will still serve to stifle such inclinations.

\section{Authorization without orders: the chain of authority}

As we have seen, each link in the chain of authority—executive, administrative, force command, TPCC and sometimes the troops themselves—-must take into account specific (and sometimes unique) factors regarding the use of robust force. Because each level wields such discretion, higher levels in the chain cannot give orders; they usually only deliver authorization or exhortation. True, since 2000 Security Council peacekeeping mandates have shifted from allowing protection towards requiring it. ${ }^{38}$ However, the fact remains that positive pressure to secure an objective does not move down a chain of command as it would in a normal military operation. Instead of a chain of command, there is a 'chain of authority'. In situations where each level wields an effective veto over robust action, the most cautious link in the chain will prove decisive. As an added difficulty, many of the factors considered by these different decision-makers shift over time as context changes—-meaning decisionmakers can resist endorsing a standing consent to engage. As a result, each actor at each link in the chain can want an active role in decision-making in any given instance. Until they do enter the decision-making process, other actors may act conservatively out of respect for their presumptive concerns. 
In sum, the iterative nature of the decision process grants each level a potential veto over robust protective action (though this will not always be true with respect to the final link: peacekeeping troops will sometimes have little discretion over what action occurs). This effective veto, combined with the variability in information, $S$ and $\beta$ used by each decisionmaker, creates an environment where peacekeepers on the ground are less (rather than more) likely to use robust force. To clarify, not all the actors in the chain of authority tend to be conservative. However, in any given case, we can usually expect the most conservative actor to possess something close to an effective veto on the use of force.

What justifies this expectation? Simply, all the factors marshalled above represent commonsense concerns possessed by decision-makers at each level, and prior reports and commentary on peacekeeping underscore that each of these factors has in fact historically stymied robust protection (we drew the factors from reports on the Balkans, Cambodia, Côte d'Ivoire, DRC, Haiti, Rwanda, Somalia and Sudan). Moreover, the existing structure of decision-making allowing for discretion at each level remains in place; each UN protective PKO necessarily involves Security Council authorization, Secretariat administration, local force-command, countries contributing troops, and the troops themselves. Certainly, force-command (and occasionally the administrative level) retains the central decision-making authority. But TPCC’s still wield final authority on the actions of their troops, troops at the coalface often still possess means to avoid force, and administrative and executive level decision-makers can still respond furiously to specific operational decisions. In short, barring further measures specifically addressing the iterative nature of the decision-making process (and we shortly investigate some promising advances) we can expect the chain of authority to continue privileging the most conservative actor. ${ }^{39}$ Ultimately, the capability to employ force to protect civilians proves only as strong as the chain's weakest link. 
The history of cases where major PKOs have pro-actively employed robust force also reflects this decision-making process. ${ }^{40}$ In Alan Doss's analysis of the pro-active uses of robust force by the major protective PKOs in Sierra Leone, Côte d'Ivoire, Liberia, and the DRC, the use of force routinely followed from prior protection failures. ${ }^{41}$ These failures were usually accompanied by allegations that the PKO was failing its mandate and a consensus condemning the specific groups brutalizing civilians. While horrific, the attacks on civilians crystallized the stakes of not responding forcefully, and demonstrated unequivocally the brutal intentions of belligerent groups. These incidents often helped turn local authorities, national governments and regional actors against the belligerents, improving the tenability of a forceful response. At the administrative level, the Secretary-General spoke out on the need for better protection in the wake of the failures. At the executive level, the Security Council followed with stronger mandates, often increasing the mission's personnel or authorizing intervention by other military forces (e.g. the British in Sierra Leone, the French in Côte d'Ivoire). TPCCs then committed these further personnel in the context of a shared understanding that the use of force had become unavoidable. With all of these layers in agreement, and swelling with fresh personnel and additional attack units, the PKOs in each case pro-actively employed robust force to protect civilians. While these processes took months if not years, with expectations and capacities honed over long periods, the decisionmaking response to atrocities can accelerate. Within days of M23's attacks on civilians in the DRC in July 2012, local force commanders, for example, the Secretary-General and the Security Council all spoke out. ${ }^{42}$ With all the levels in clear agreement, a robust response followed swiftly. 
Belligerents' motives for targeting civilians

The local belligerents' will and capacity for committing atrocities opposes the chain of authority. Both governments and non-state actors can find themselves in situations where attacking civilians seems necessary—for ideological, organizational, geographic or geopolitical reasons. For example, ethnic cleansing of an area can expand territory. ${ }^{43}$ Stateactors performing atrocities on civilians can undermine insurgents by destroying their civilian bases of operation. For their part, as Weinstein describes, rebels can adopt differing policies of protecting or terrorizing civilian populations, depending on the resources available to the insurgency, and the nature of its members. ${ }^{44}$ Local belligerents may gain privately from assaulting civilians; for example, seizing property and booty, making money through protection racketeering, settling prior grievances, or taking girls as 'war-wives' and children as future soldiers, to say nothing of direct motivations for rape and torture. ${ }^{45}$ As a result, belligerents' motives to do violence to civilians can exceed peacekeepers’ motivations to protect them. Belligerents can behave like soldiers in a war, willing to risk their lives in order to engage PKOs and access civilians. Despite myriad cases of peacekeeper bravery, this asymmetry recurs, making a difference directly in terms of the will to act, and indirectly with respect to which side in negotiations can make the most credible threats of unleashing lethal force.

\section{Policy initiatives, Resolution 2098 and ways forward}

Our analysis helps demonstrate the substantial challenges involved in peacekeeping protection of civilians. Many of these problems have no easy fixes. The foregoing section sets down legitimate reasons why different decision-makers must retain discretion over the use of force to protect civilians. This result reinforces a familiar message: peacekeeping does not provide a universal solution for every problem, and even in cases where peacekeeping 
furnishes one part of the solution, the use of increased force may foment more problems than it resolves.

Even so, the foregoing analysis and the iterative chain of authority suggest several avenues for improvement. The more the decisions at each level mirror each other, the less conservative outliers will stymie action, and the greater promise for welding together links in the chain of authority. Protection improves when each authority in the chain possesses roughly similar information of similar sensitivity, and attributes similar costs and benefits to each of the four possible outcomes: hits, correct rejections, misses and false alarms. Securing this objective implies three ways forward. Objective 1: We need to align information and its sensitivity $(S)$ by ensuring that information flows effectively throughout the chain of authority, putting every actor on the same page regarding the situation on the ground and likely risks to civilians. Objective 2: We need to assuage each decision-maker's particular concerns in order to align the costs and benefits each actor attributes to hits, correct rejections, misses and false alarms, and so align their values for $\beta$. Objective 3 : We need to amalgamate links in the chain of authority so each decision-maker does not need to act conservatively out of presumptive concerns for another party.

The final part of this paper surveys three important recent initiatives for peacekeeper's protection of civilians and assesses how these initiatives promote or undermine these three objectives.

Responsibility while protecting

Brazil’s 2011 concept note 'Responsibility While Protecting' ${ }^{46}$ specifically targeted the Security Council-mandated NATO intervention into Libya, but the principle applies to all robust international protection efforts. Now we can hardly take issue with the basic theme of responsibility while protecting. The principle sensibly observes that international 
responsibility does not end with a decision to intervene, but must ensure interventions mitigate all harms to civilians. However, the note focuses almost exclusively on the costs of action. Even in the explicit context of Rwanda, it allows only that there may be situations where the international community might contemplate robust action. Equally, its proposals to give the Security Council procedures to monitor and assess the implementation of resolutions threaten to increase Council micromanagement of peacekeepers and augment the Council's role as veto-holders in the chain of authority. In introducing the note, Brazil went so far as to recommend a 'first, do no harm' motto for those protecting civilians, announcing that 'one casualty is too many'. ${ }^{47}$ If taken literally, such strictures would bring all peacekeeper efforts to robustly protect civilians to a grinding halt. Even without official implementation, such maxims place moral standards on protective PKOs that they cannot possibly meet, and thus heighten the conservatism of lower level decision-makers.

Ultimately, the foregoing SDT analysis shows that exhortation to alter priorities at one level, on its own, can only serve to shift the intervention threshold, $\beta$. We need to balance legitimate concern about mistaken interventions (false alarms) with the awareness that raising $\beta$ necessarily increases the risk of catastrophic failures to intervene (misses).

\section{Protection of civilians coordination mechanisms}

The iterative nature of the decision process offers the promise of real improvement through increased coordination and shared decision-making. The 2012 DPKO and DFS report on Protection of Civilians Coordination Mechanisms in UN Peacekeeping Missions provides an example of the possibilities. ${ }^{48}$ At first blush, the reader might wonder why coordination mechanisms prove so central to peacekeeping protection activities that they warrant their own report. After all, reports rarely study PKO internal coordination mechanisms more generally. ${ }^{49}$ The foregoing SDT analysis, however, provides a theory-based platform for 
appreciating what the report described empirically: that good coordination impacts profoundly on effective civilian protection.

As we have seen, protective action by peacekeepers occurs in a decentralized fashion; it involves ground-level decision-making by myriad actors dispersed throughout the operation. At the same time, protection actions can ignite systemic outcomes, such as belligerents deciding the operation has become a party to the conflict. The decentralization flows from the need for discretion and autonomy in the field, while the system-wide implications demand centralized doctrine and integrated strategic awareness. The better the coordination between these decision-making nodes, the greater the prospects for civilian protection efforts.

The report recounts the inventive ways PKOs evolved to meet this coordination challenge, often employing a dedicated, high-level and well-resourced protection of civilians coordinator, combined with regular multilevel forums discussing protection policy, threats and strategies. As the foregoing analysis implies, and as the report describes, the issue here goes beyond mere information sharing and situational analysis (Objective 1, above), to ensure that each actor adheres to a larger shared vision of civilian protection (Objective 2), and that peacekeepers in the field can be confident they know at any given moment whether a given action has the support of central decision-makers (Objective 3).

Our analysis of the at-once-decentralized-and-systemic nature of protection decisions thus provides a theoretical basis for the report, and underscores why its findings should be taken seriously. Even so, in the context of the iterative chain of authority, the report carried scope limitations. Even if we increase coordination inside the mission, we still need to integrate decision-makers in the chain of authority outside the PKO_especially the Security Council and TPCCs. The importance of these actors emerges in a major recent intervention decision of the Security Council. 
In Resolution 2098 of 28 March 2013 the Security Council expanded the mandate of MONUSCO in the DRC and authorized the formation of an 'Intervention Brigade'. The Council tasked this force with undertaking 'offensive operations ... in a robust, highly mobile and versatile manner' in order to 'neutralize' armed groups. ${ }^{50}$ Even bearing in mind the long history of peacekeeping in the DRC, ${ }^{51}$ on any measure Resolution 2098 is proactive in its authorization of offensive force. The Council recognized the revolutionary nature of its proposal, emphasizing it was working on 'an exceptional basis ... without creating a precedent or any prejudice to the agreed principles of peacekeeping' ${ }^{52}$ As distinct from the previously mentioned pro-active use of force in Côte d'Ivoire, the Council itself directly mandated the offensive action, and authorized the use of force against specific groups even when those groups are not in the actual process of attacking civilians.

However, while the Council unanimously passed the resolution, the foregoing analysis reveals several areas of concern in Resolution 2098's text and accompanying statements.

Council members disagreed on how far Resolution 2098 integrates together the Intervention Brigade and MONUSCO’s regular forces. The United Kingdom (UK) applauded the level of integration, declaring that, 'It is one Mission with one mandate, one Special Representative and one Force Commander’. ${ }^{53}$ Guatemala agreed that Resolution 2098 had not separated the Intervention Brigade from MONUSCO, but objected that a 'self-contained unit with specific responsibilities’ would have been preferable. ${ }^{54}$ For its part, Rwanda rejected both views, and praised the Intervention Brigade’s ‘clear separation' ${ }^{55}$ The foregoing analysis helps illustrate the grounds of these conflicting concerns. Discrete protective actions by one element can generate system-wide consequences for the entire operation. This feature presses both for and against integration. The representatives of both Rwanda and Guatemala desired a clear 
separation—a separation that could have quarantined MONUSCO’s more general activities and personnel from association with the Intervention Brigade's offensive use of force. In that way, MONUSCO could have remained an ordinary (albeit robust) peacekeeping operation, still perceived as neutral and impartial by all parties. However, the UK's emphasis on the integrated nature of the Brigade and MONUSCO also makes sense. Without close strategic coordination, the Intervention Brigade’s offensive operations could easily disrupt MONUSCO’s activities, and even trigger new dangers to civilians. ${ }^{56}$ Although both positions possess their own advantages, the UK's vision appeared to win out. This appears a sensible result-experience suggests that parties to the conflict undertake reprisals against whatever targets they can access, meaning that an operational separation between the two elements may not have improved matters. ${ }^{57}$ If opposition forces will view MONUSCO and the Intervention Brigade as integrated in any case, then it makes sense to secure the benefits of coordinated operation from integration.

Council members also disagreed on the Brigade's use of offensive force. Although the increasing robustness of many PKO mandates has smeared any easy distinction between peacekeeping and peace enforcement, the Intervention Brigade clearly falls into the latter category.

The Security Council explicitly directed the Brigade to 'neutralize' specific armed groups in order to reduce 'the threat posed by [them] to state authority ... ${ }^{58}$ Despite the controversy of this directive, the Council's unanimous agreement on the text helps to weld together links in the chain of authority, implying that members of the Intervention Brigade can be confident they enjoy the Council's full support in their difficult task. However, ambiguities within the mandate, combined with statements by member states, belie this appearance. Although the Council reaffirmed the principles of peacekeeping in the resolution’s preamble, it later 
declared that the Intervention Brigade was tasked without 'prejudice to the agreed principles of peacekeeping' ${ }^{59}$ This implies that the Intervention Brigade’s mandate does not align with those principles (hence the need to declare its exceptional and non-precedent-setting nature ${ }^{60}$ ). Yet other Council Members's statements implied that the mission's mandate had been 'carefully limited' to observe the basic UN peacekeeping principles. ${ }^{61}$ For its part, Pakistan felt the resolution contained sufficient ambiguities to warrant the country placing its own 'interpretation' on the official record. Given these ambiguities and conflicting interpretations, decision-makers within the Intervention Brigade may be unsure what actions Council members will support, even with respect to fundamental questions such as the operative peacekeeping principles.

Ultimately, while 'creative ambiguity' has long been used by the Security Council to paper over differences and produce workable agreements, the iterative chain of authority shows why this tactic must be resisted in the context of authorizing PKO’s robust use of force. Without genuine consensus and explicit direction on protection of civilians from the Security Council, later actors may act conservatively in order to accord with the presumptive concerns of decision-makers higher in the chain of authority. That is, ambiguity in high-level support may induce low-level actors to interpret their mandate conservatively.

As well as the text itself, the process leading to Resolution 2098 could have been improved in order to better respond to the concerns of the last, crucial link in the chain of authority: TPCCs. The three countries voicing the gravest concerns about Resolution 2098-Pakistan, Argentina and Guatemala—all expressed concerns about the safety and security of peacekeepers, and the legitimate concerns troop contributors might have about the new mandate. All three countries regularly commit personnel to PKOs, and two of them contribute to MONUSCO itself. Both Guatemala and Argentina castigated the process, 
arguing that more time should have been devoted to the discussion, and that consultations were not sufficiently comprehensive or inclusive. ${ }^{62}$ Having itself lost eight MONUSCO personnel in 2008, Guatemala’s representative questioned whether the Guatemalan people would prove understanding of similar sacrifices made 'combating insurgents in a distant country while trying to undertake a role that clearly falls to the national army of that country'. ${ }^{63}$ Unquestionably, TPCCs hold legitimate concerns about peacekeeper safety. If Council decision-making fails to incorporate those concerns (especially in the fortunate case where the Security Council includes several TPCCs from the PKO) then we can expect these concerns to raise their heads later in the process of intervention decision-making. At that point, however, the resolution is fixed, and TPCC concerns might forge a disconnect between the Council mandate and the operation of the PKO or (worse still) impel TPCCs to withdraw their troops. Compared to other member states, TPCCs carry greater burdens in terms of the loss of personnel and reputation. Incorporating their legitimate concerns into the crafting of the mandate helps weld together links in the chain of authority, expediting later decisionmaking.

\section{Conclusion}

By focusing attention on recurring elements of the decision-making process (the quantity and quality $(S)$ of information, and the different factors determining the intervention threshold, $\beta$ ), SDT helps us see how decision-making differs for differently placed agents. Those differences prove decisive when each agent in an iterative decision-process holds a veto on action: conservative concerns at one level can work to stymie courageous and pro-active leadership at another. Our analysis offers no easy solutions—_stymieing', after all, sometimes prevents unnecessary and potentially disastrous interventions. But the analysis does reveal why, in the context of the robust use of force, coordination, communication and attempts to 
achieve prior consent can prove as important as helicopters, rifles and boots on the ground. As we have seen, agents cannot make decisions to use force in isolation. Such decisions can carry life-or-death stakes for vulnerable local civilians, can ignite systemic implications across the mission as a whole, and sometimes even ramify onto the world stage. While each agent at each level must retain discretionary input into the use of robust force, we can hope to improve the way information, consent and support flow through the larger decision-making super-structure to promote more effective protection.

\footnotetext{
${ }^{1}$ We use the acronym 'PKO' throughout as a shorthand for any type of peacekeeping or peace-enforcement operation. 'Peace enforcement' departs from more traditional 'peacekeeping' insofar as the former mandates the use of robust force to secure mission objectives. (This usage is not univocal. E.g. Damien Lilly, "The Changing Nature of the Protection of Civilians in International Peace Operations", International Peacekeeping 19(5)
} (2012): 628-39.) We employ the term 'robust force' to connote deliberate lethal force employed against belligerents. In turn, 'belligerents' refers to all armed actors who, for any reason, attempt to directly harm civilians, including insurgents, regular troops, militia, violent mobs, and local, unaffiliated tribal forces.

${ }^{2}$ UNSC, Meeting: The Situation Concerning the Democratic Republic of the Congo, S/PV.6943, 28 March 2013, p. 5.

${ }^{3}$ For instance, theorists have applied SDT to aircraft mishap investigations, medical intervention judgments, occupational hazard management, drug trials and various socialpsychological applications. See, e.g., Otto Bjoertomt et al., "'Noisy Patients'--Can Signal Detection Theory Help?", Nature Clinical Practice Neurology 4(6) (2008): 1105-20; Tariq Sami Adbelhamid, Puneet Narang, and Don W. Schafer, "Quantifying Workers’ Hazard Identification Using Fuzzy Signal Detection Theory", The Open Occupational Health \& 
Safety Journal 3(Suppl 1-M3) (2011): 18-30; Manfred Hauben, Lester Reich, and Stephanie Chung, "Postmarketing Surveillance of Potentially Fatal Reactions to Oncology Drugs: Potential Utility of Two Signal-Detection Algorithms", European Journal of Clinical Pharmacology 60 (2004): 747-50.

${ }^{4}$ Sidney Dekker and David Woods, "To Intervene or Not to Intervene: The Dilemma of Management by Exception", Cognition, Technology and Work 1(2) (1999): 86-96; Jose Kerstholt et al., "The Effect of a Priori Probability and Complexity on Decision Making in a Supervisory Control Task", Human Factors 38(1) (1996): 65-78.

${ }^{5}$ In formal SDT, sensitivity is signified by d'. We avoid employing the technical or quantitative terms of SDT, but in brief, the sensitivity d' refers to the ability of the decisionmaker to discriminate signal from noise on their input channel(s). The sensitivity, d', is calculated as a function of the normalized distance between the means of the noise and signal-plus-noise distributions: $d^{\prime}=(\mu \mathrm{n}-\mu \mathrm{s}+\mathrm{n}) / \sigma$. The more these distributions overlap, the less the normalized distance, and the lower the sensitivity. In other words, when signal and noise are hard to distinguish, information quality decreases.

${ }^{6}$ E.g. investigating troop contributing countries’ decision-making: Vincenzo Bove and Leandro Elia, "Supplying Peace: Participation in and Troop Contribution to Peacekeeping Missions", Journal of Peace Research 48 (2011): 699-714.

${ }^{7}$ As it did, for example, in UNSC, Res. 1894 (Protection of Civilians in Armed Conflict), S/RES/1894, 11 November 2009.

${ }^{8}$ UN Secretary-General, "Statement by the Secretary-General on the Situation in Côte D'ivoire," 4th April, 2011.

${ }^{9}$ Alex Bellamy and Paul Williams, "The New Politics of Protection? Côte D’ivoire, Libya and the Responsibility to Protect", International Affairs 87(4) (2011): 825-50.

${ }^{10}$ Guatemala (see n. 2 above), p. 4. 
${ }^{11}$ As occurred, arguably, in Côte d'Ivoire. Bellamy and Williams (see n. 9 above).

${ }^{12}$ Boutros Boutros-Ghali, Supplement to an Agenda for Peace, A/50/60-S/1995/1, 3 January 1995, paras 34-36. See also Marrack Goulding, "The Use of Force by the United Nations", International Peacekeeping 3(1) (1996): 1-18, pp. 10-15.

${ }^{13}$ Nick Grono, "Briefing - Darfur: The International Community's Failure to Protect", African Affairs 105(421) (2006): 621-31.

${ }^{14}$ Romeo Dallaire, Shake Hands with the Devil: The Failure of Humanity in Rwanda (New York: Carroll and Graf, 2003).

${ }^{15}$ Frédéric Mégret, "Beyond the 'Salvation' Paradigm: Responsibility to Protect (Others) vs the Power of Protecting Oneself", Security Dialogue 40(6) (2009): 575-95, p. 586.

${ }^{16}$ Katarina Månsson, "Use of Force and Civilian Protection: Peace Operations in the Congo", International Peacekeeping 12(4) (2005): 503-19, p. 512.

${ }^{17}$ James Turner Johnson, "Maintaining the Protection of Non-Combatants", Journal of Peace Research 37 (2000): 421-48, p. 447.

${ }^{18}$ Eirin Mobekk, "Security Sector Reform and the UN Mission in the Democratic Republic of Congo: Protecting Civilians in the East", International Peacekeeping 16(2) (2009): 272-86, pp. 275-6.

${ }^{19}$ Goulding (see n. 12 above), p. 9.

${ }^{20}$ Rupert Smith, The Utility of Force: The Art of War in the Modern World (New York: Penguin, 2006), p. 337.

${ }^{21}$ Dallaire (see n. 14 above), pp. 160-61.

${ }^{22}$ Because the legal risks present only one factor among many, PKOs generally limit their use of force far beyond such constraints. See, e.g., Christopher K. Penny, "‘Drop That or I'll Shoot ... Maybe': International Law and the Use of Deadly Force to Defend Property in UN Peace Operations", International Peacekeeping 14(3) (2007): 353-67. 
${ }^{23}$ Victoria Holt and Tobias Berkman, The Impossible Mandate? Military Preparedness, the Responsibility to Protect and Modern Peace Operations (Washington: The Henry L. Stimson Center, 2006), p. 97.

${ }^{24}$ Ibid., pp. 98-99.

${ }^{25}$ Victoria Holt, Glyn Taylor, and Max Kelly, Protecting Civilians in the Context of UN

Peacekeeping Operations: Successes, Setbacks and Remaining Challenges (New York: DPKO, OCHA, 2009), p. 168.

${ }^{26}$ John Sanderson, "Command at the Operational Level," in Presentation to the Australian Command and Staff College (Queenscliff Australia: 2000).

${ }^{27}$ That said, contribution decisions interact with peacekeeper deaths in complex ways: Bove and Elia (see n. 6 above).

${ }^{28}$ Guatemala’s statement on Res. 2098 makes this explicit: UNSC (see n.2 above), p. 4.

${ }^{29}$ Siobhán Wills, Protecting Civilians: The Obligations of Peacekeepers (Oxford: Oxford University Press, 2009), p. 35.

${ }^{30}$ Security Council Report SCR, Special Research Report: Security Council Action under Chapter VII: Myths and Realities, 2008 No. 1, 23 June 2008, p. 27.

${ }^{31}$ DPKO/DFS, Lessons Learned Note on the Protection of Civilians in United Nations Peacekeeping Operations: Dilemmas, Emerging Practices and Lessons, 2010, p. 19.

${ }^{32}$ Holt and Berkman (see n. 23 above), pp. 159-160, 172.

${ }^{33} \mathrm{UN}$, Report of the Independent Inquiry into the Actions of the United Nations During the 1994 Genocide in Rwanda, UN Doc S/1999/1257/Annex, 16 December, 1999, p. 39. ${ }^{34}$ DPKO/DFS, Protection of Civilians Coordination Mechanisms in UN Peacekeeping Missions (New York: United Nations, 2012), p. 14. 
${ }^{35}$ The harshest criticisms of PKOs in Rwanda and Srebrenica focus on local forces’ failure to pass on information about risks to civilians. For example, UN Rwanda Report (see n. 33 above), p. 474; Holt and Berkman (see n. 23 above), p. 91.

${ }^{36}$ Dallaire (see n.14 above), pp. 243-44.

${ }^{37}$ Perhaps in the spirit of Sandra Whitworth's feminist analysis of peacekeeping military culture: Sandra Whitworth, Men, Militarism, and UN Peacekeeping: A Gendered Analysis (London: Lynne Rienner Publishers, 2004).

${ }^{38}$ See, in the context of DRC, Månsson (see n.16 above), p. 514.

${ }^{39}$ This result contrasts with some other applications where SDT has shed light on decisionmaker's preferences and criteria where structures and incentives tended to favor riskier criterion-setting (e.g. Hauben et al. (see n. 3 above)).

${ }^{40}$ The chain of authority also explains why we might expect TPCCs operating outside the cumbersome decision-making process to take sudden unilateral decisions to escalate force, e.g. the action of the British operation in Sierra Leone in 2000 to recover hostages from the West Side Boys.

${ }^{41}$ Alan Doss, Great Expectations: UN Peacekeeping, Civilian Protection, and the Use of Force, GCSP Geneva Papers: No. 4 (Geneva: Geneva Centre for Security Policy, 2011), pp. 14-25, 30-31.

42 "UN Mission Using Helicopters to Protect Civilians from Rebel Fighters in DR Congo." UN News Centre, 13 July 2012. http://www.un.org/apps/news/story.asp?NewsID=42475\#.Uyk3Maja58F.

${ }^{43}$ Alexander Downes, Targeting Civilians in War (London: Cornell University Press, 2008), p. 38.

${ }^{44}$ Jeremy M. Weinstein, Inside Rebellion: The Politics of Insurgent Violence (New York: Cambridge, 2007). 
45 Johnson (see n.17 above), p. 435.

${ }^{46}$ Brazil, Concept Note: Responsibility While Protecting: Elements for the Development and Promotion of a Concept (New York: United Nations, 2011).

${ }^{47}$ UNSC, Meeting: Protection of Civilians in Armed Conflict, S/PV.6650, 9 November 2011, pp. 16-17.

${ }^{48}$ DPKO/DFS (see n. 34 above).

${ }^{49}$ DPKO/DFS (see n. 34 above), p. 10.

${ }^{50}$ UNSC, Res. 2098 (DRC), S/RES/2098, 28 March 2013, paras 9, 12(b).

${ }^{51}$ Månsson (see n. 16 above), esp. pp. 510-11.

${ }^{52}$ UNSC (see n. 50 above), para. 9.

${ }^{53}$ UNSC (see n. 2 above), p. 5.

${ }^{54}$ UNSC (see n. 2 above), p. 4.

${ }^{55}$ UNSC (see n. 2 above), p. 3.

${ }^{56}$ UN Secretary-General, Special Report of the Secretary-General on the Democratic Republic of the Congo and the Great Lakes Region, S/2013/119, 27 February 2013, para. 63.

Problems arose from the lack of integration between the previous EU force and MONUC:

Månsson (see n.16 above), p. 511.

${ }^{57}$ Goulding (see n.12 above), p. 9.

${ }^{58}$ UNSC (see n. 50 above), para. 9. Arguably, MONUSCO was already a party to the conflict: Lilly (see n. 1 above), p. 633; Mobekk (see n. 18 above), p. 275.

${ }^{59}$ UNSC (see n. 50 above), para. 9.

${ }^{60}$ See the statement by China. UNSC (see n. 2 above), p. 8

${ }^{61}$ UNSC (see n. 2 above), p. 10. (Russia)

${ }^{62}$ UNSC (see n. 2 above), p. 4-6.

${ }^{63}$ UNSC (see n. 2 above), p. 4. 